\title{
ANALYSIS OF PARTICULATE MATTER COMPOSITION
}

According to current research, particulate matter (PM) has a negative impact on citizens in particular (respiratory and cardiovascular diseases). Based on EU studies, deaths of 347,900 Europeans are attributable to air pollution. Formation of particulate matter from road transport has been a concern for big cities in particular.

For long time monitoring PM we choosed the sections of roads located both within urban areas and rural areas were selected for longterm monitoring, differing in particular by the surface of the roadway - either with asphalt concrete paving $(A C)$ or with stone mastic asphalt (SMA) paving, an asphalt compound with disintegrated stone grade and a higher percentage of asphalt binder.

We were executed the Air Samples with using medium-volume LECKEL MVS6 sampling pump.

Keywords: traffic, emissions, environment, monitoring, PM10

\section{Introduction}

Considering the predominant use of combustion engines, exhaust gases contain high amount of both gaseous and solid contaminants. They include high quantities of the finest fractions that can stay in the air for a long time; they can easily enter the respiratory tract and be harmful to human health.

The Faculty of Civil Engineering of the University of Zilina, Department of Highway Engineering has participated in the international project "SPENS Sustainable Pavements for European New Member States" [3] aimed at sustainable transport and focusing on evaluation of effects of different types of roadways on generation of particulates caused by transport. The Department continues this focus also in research activities of the Centre of Excellence for Systems and Services of Intelligent Transport.
The aim of this part of the work to be presented is to compare development of particulate matter and its composition along roads depending on surface type of the road.

\section{Particulate Matter Monitoring}

Sites representing both non-urban and urban roads with various traffic volumes and various surface types were selected to monitor concentrations of specific fractions of the particulate matter at locations with different traffic volume.

Air samples were taken using medium-volume LECKEL MVS6 sampling pumps. The devices are intended for outdoor use at high or low temperatures. The flow of the air to be taken is controlled and basic physical parameters are maintained by means of a ther-
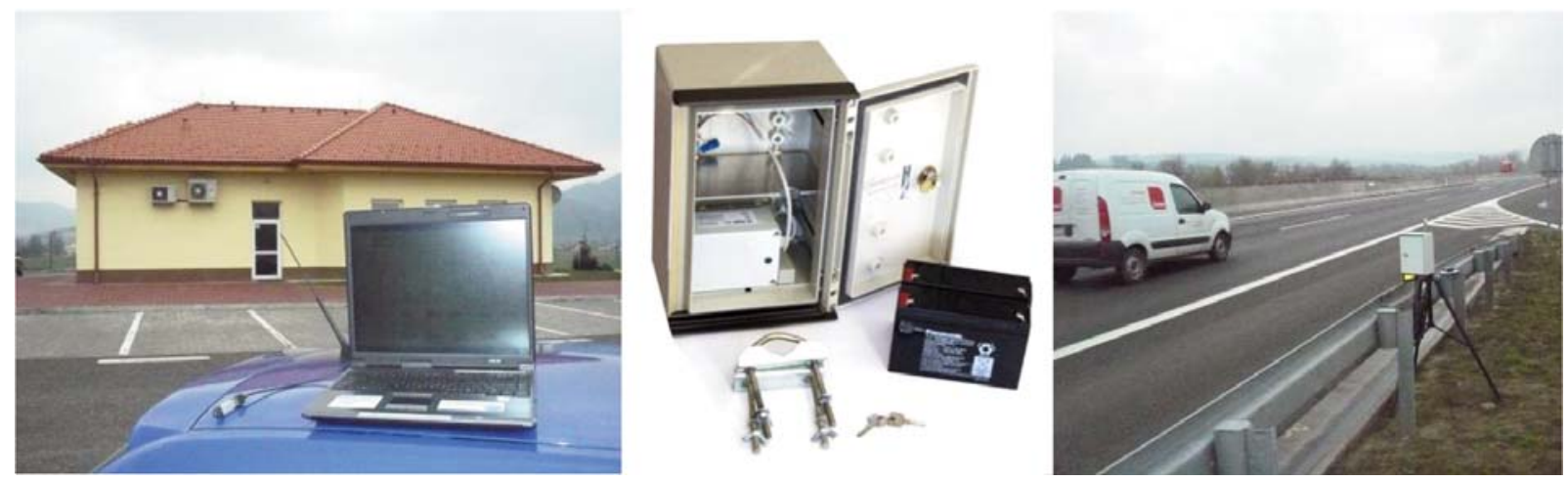

Fig. 1 Automatic system for traffic intensiveness monitoring (SIERZEGA SR4)

\footnotetext{
* Daniela Durcanska

Faculty of Civil Engineering, University of Zilina, Slovakia, E-mail: daniela.durcanska@fstav.uniza.sk
} 

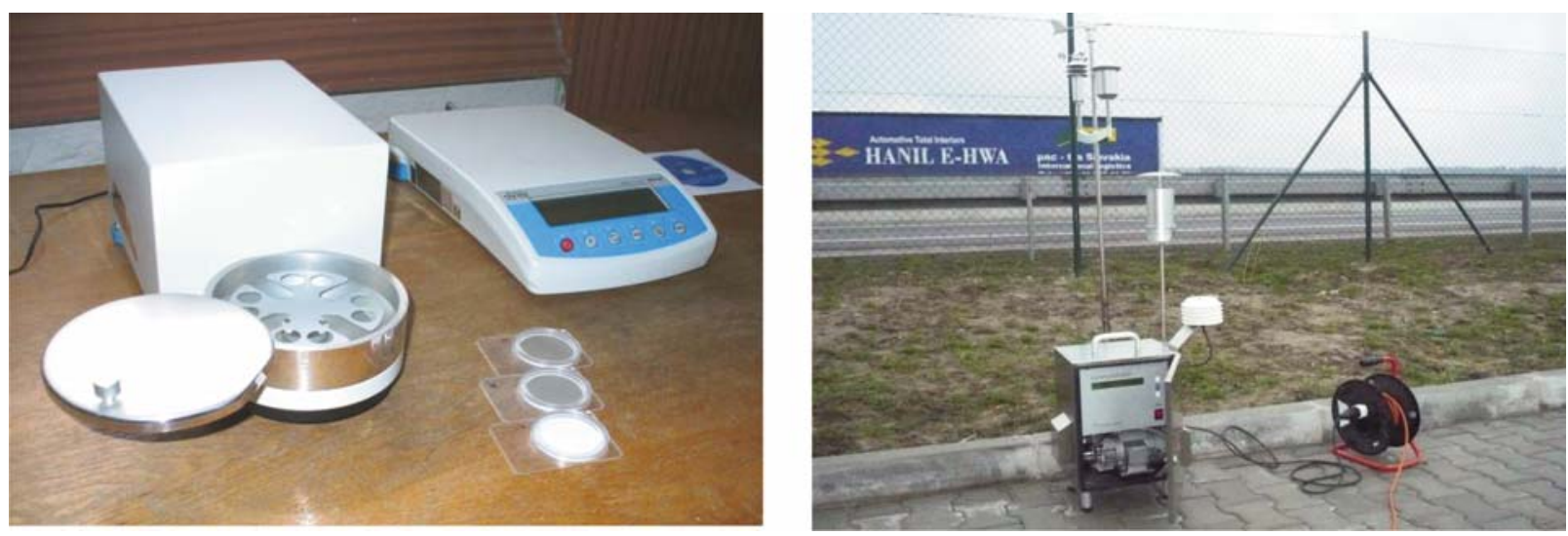

Fig. 2 Filter weighing by means of analytical scales (left); measuring position by the D1 highway (right)

mally compensated slot. PM capturing filters are inserted between Teflon holders into a sampling head forming an integral part of the device. Filters from nitrocellulose fibres were used to capture PM (Fig. 2).

Measurements were taken in compliance with the European standards EN 12341 [8] and EN14907 [9] where this methodology is used as a reference method.

- Particle concentrations were determined gravimetrically from every exposed filter. Traffic volume was recorded continuously using an automatic traffic intensiveness detector SIERZEGA SR4. Detector - the microwave radar Works at the base of dopplers principle (Fig. 1).

Multiple measurements were taken at four sites between 2007 and 2009. Most measurements focused on PM10 monitoring. Representation of different particles was monitored at two sites in July and October 2008, taking samples to monitor chemical composition of PM.

The positions were selected as follows (Fig. 3):

1. D1 highway, Predmier - four-lane road, surface - stone mastic asphalt (SMA);

2. II/507 Bytca, bypass road - two-lane road, surface - stone mastic asphalt (SMA);

3. I/18 Zilina, city through road - four-lane road, surface - asphalt concrete (AC);

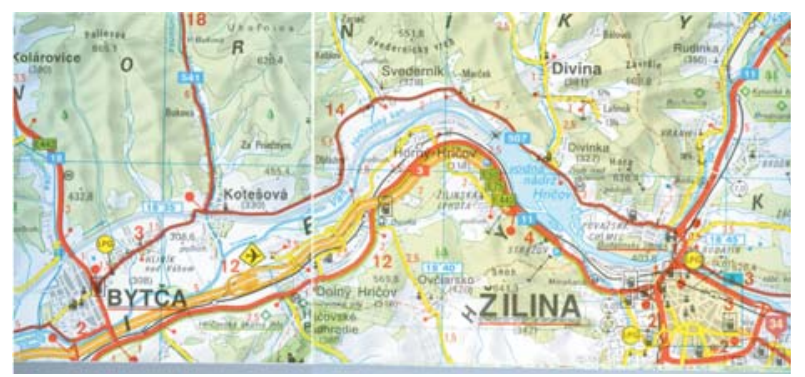

Fig. 3 Scheme showing localisation of measuring positions around the city of Zilina
4. I/18 Dolny Hricov - two-lane road, surface - asphalt concrete (AC).

Dependency between temperature and particulates concentration was shown at the monitored positions (Figs. 4 to 7), but no dependency between average values of particulates formed and total traffic volume was proven. This can be proven, for example, by the monitored section No. 4 in Dolny Hricov with the D1 highway opened early in 2008, so traffic volume at the I/18 road significantly decreased, but with no effect on PM10 particulate concentration (Fig 7).

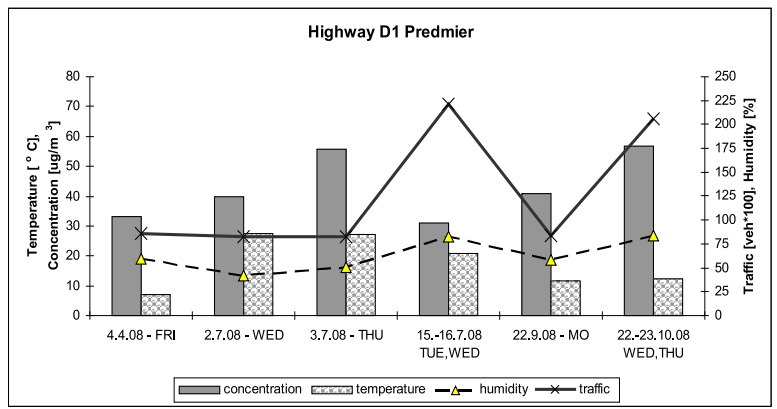

Fig. 4 Long-term observation at the measuring position 1, D1 highway, Predmier

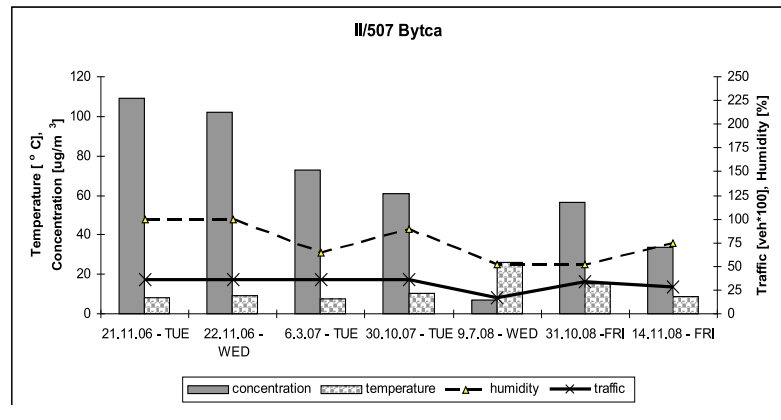

Fig. 5 Long-term observation at the measuring position 2, II/507 road, Bytca bypass

$18 \cdot$ COMMUNICATIONS 3A/2010 


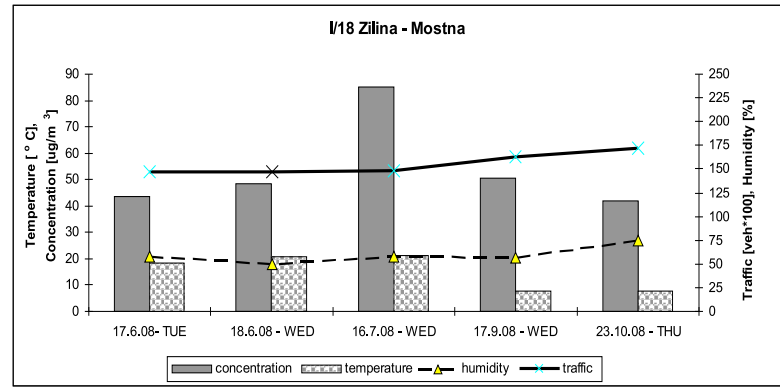

Fig. 6 Long-term observation at the measuring position 3, I/18 Zilina city through road

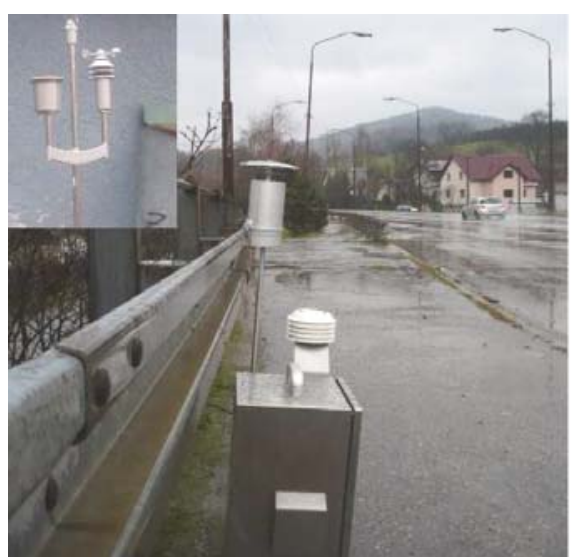

Fig. 8 Measurement at the roadway position 4 Dolny Hricov (on the left)

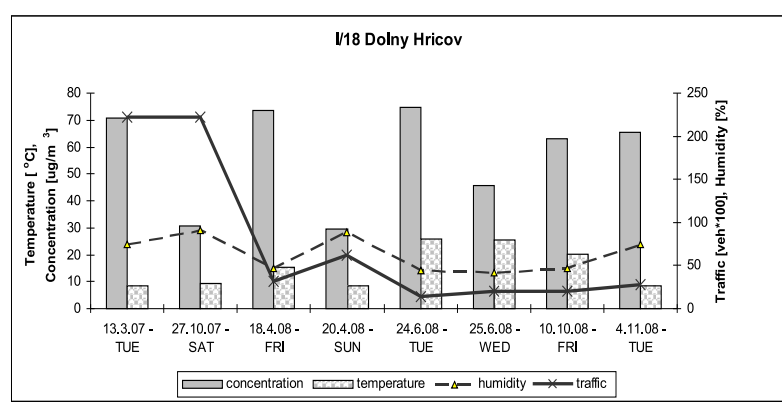

Fig. 7 Long-term observation at the measuring position 4, I/18 road Dolny Hricov

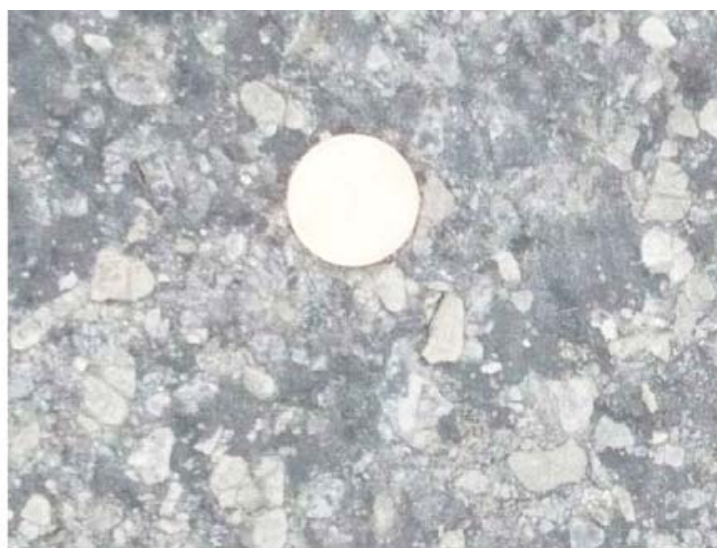

Roadway surface, asphalt concrete ACo roadway surface 11 - 15 years old (on the right)
Continuous control measurements were made using mobile monitoring equipment in cooperation with ENVItech, s.r.o. Trencin (Figs. 8 to 9). However, traffic count was done only manually during the continuous measurement. This partial measurement, on the contrary, indicates an interim dependency between the currently increasing traffic volume and the amount of PM concentration.

\section{Comparison of Surfaces on the Basis of their Qualitative Parameters}

Measurements of roadway surface roughness and analysis of surface pavement compound were done on measuring positions 2 and 4 . The measurements support results presented on monitoring
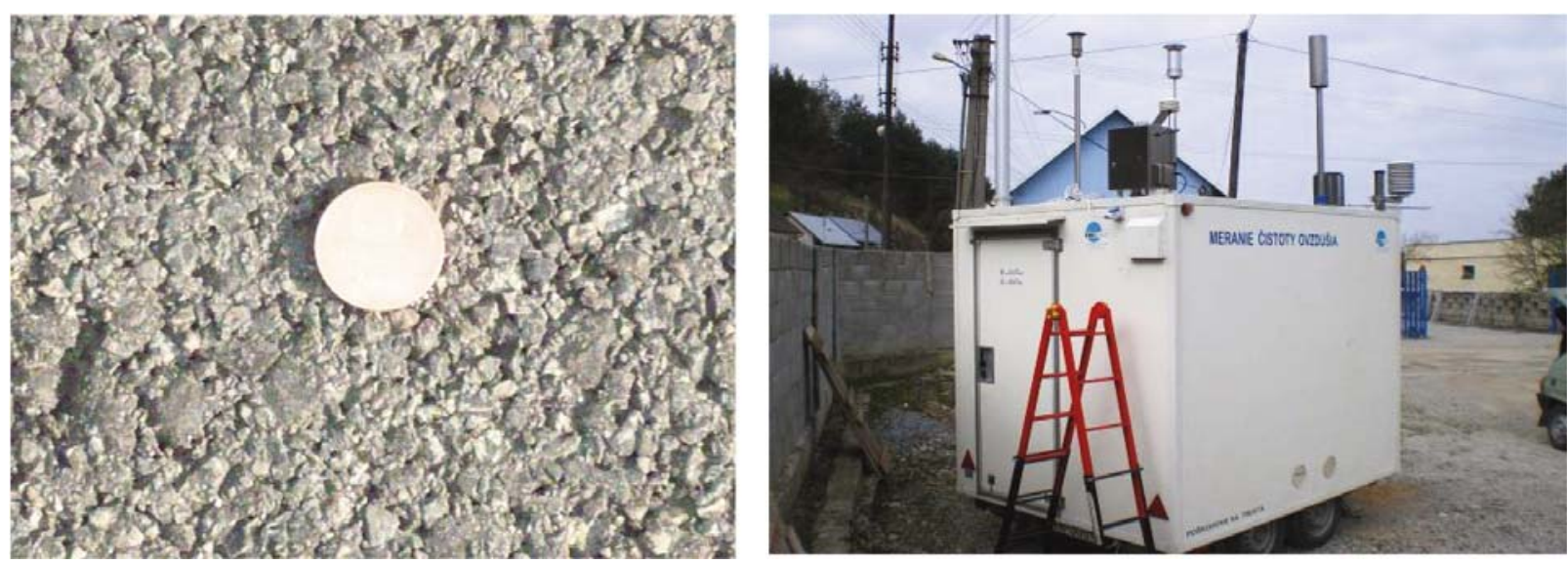

Fig. 9 Measuring at position 4 after laying down the new surface (2 weeks old); Mobile monitoring equipment by ENVItech Trencin on the right 
of particulate matter composition depending on surface pavement type.

Average results for roughness from two repeated measurements taken by Profilograph GE representing thickness of macrotexture surface are as follows:

- Mastic asphalt surface (SMA) was found to be MPD $=0.95$.. i.e. the surface is visually rougher, its grain size is larger;

- Asphalt concrete $(\mathrm{AC})$ was found to be MPD $=0.42 \ldots$ i.e. the surface is visually smoother with fine grain size.

This corresponds also to composition of the asphalt compounds: SMA - $20 \%$ share of fine fraction up to $2 \mathrm{~mm}$; AC - $50 \%$ share of fraction up to $2 \mathrm{~mm}$.

Roughness measurements by the profilograph were taken also at position 4 , observing differences between the original roadway surface and the newly laid pavement surface (made from asphalt concrete again).

Average results for roughness from two repeated measurements taken in August 2008 show that the new surface is better in terms of quality and rougher:

- the newly laid asphalt surface (AC/new) was found to be MPD $=0.80$

- the original asphalt surface (AC/old) was found to be MPD = $=0.38$.

When the new pavement surface was laid down, formation of particulate matter was reduced, probably due to a better bond between the fine aggregate and the binding material (Fig. 10).

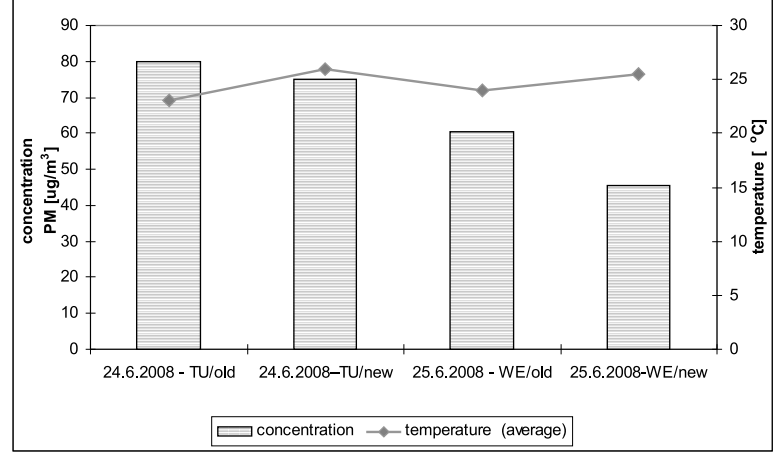

Fig. 10 Comparison of measurements of particulate matter concentrations on the original asphalt surface and the newly laid one at the Dolny Hricov position

\section{Chemical Analysis of Samples}

Chemical analyses of samples taken at position 1 were done to determine content of selected metals (ICP/MS, Agilent 7500ce). The aim was to identify differences in PM composition resulting from operation of vehicles on roads with different surfaces. To evaluate metal content in PM10 fraction we cooperated with Centrum dopravniho vyzkumu Brno (Brno Transport Research Centre).

It is assumed that inorganic particles are formed only by abrasion of cement-concrete pavements. These particles therefore represent $90 \%$ of the particles resulting from abrasion of asphaltconcrete pavements [4] and they consist mostly of coarse fraction PM.

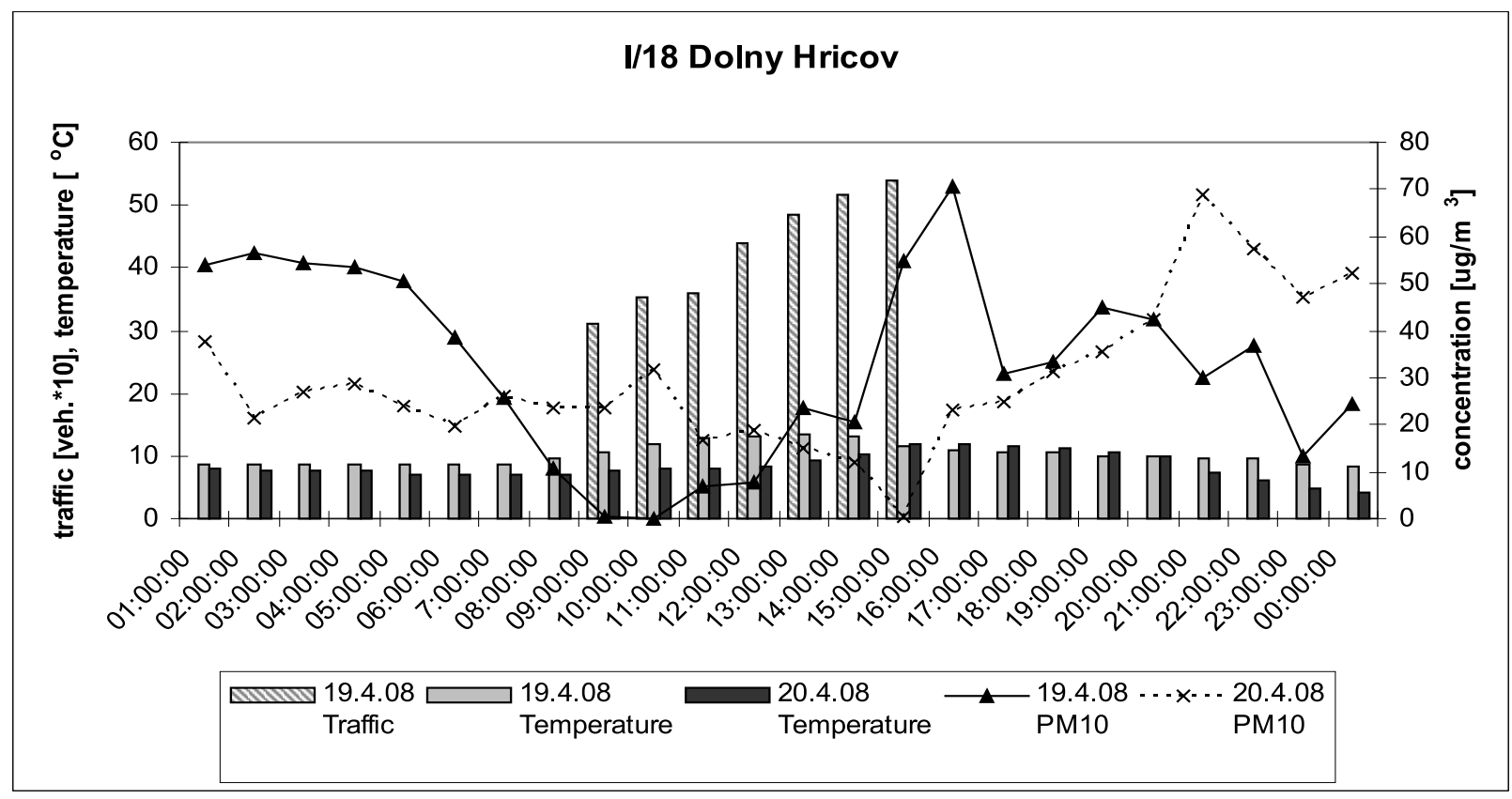

Fig. 11 Course of dependency between particulate matter PM10 formation and air temperature (position 4 - Dolny Hricov) 

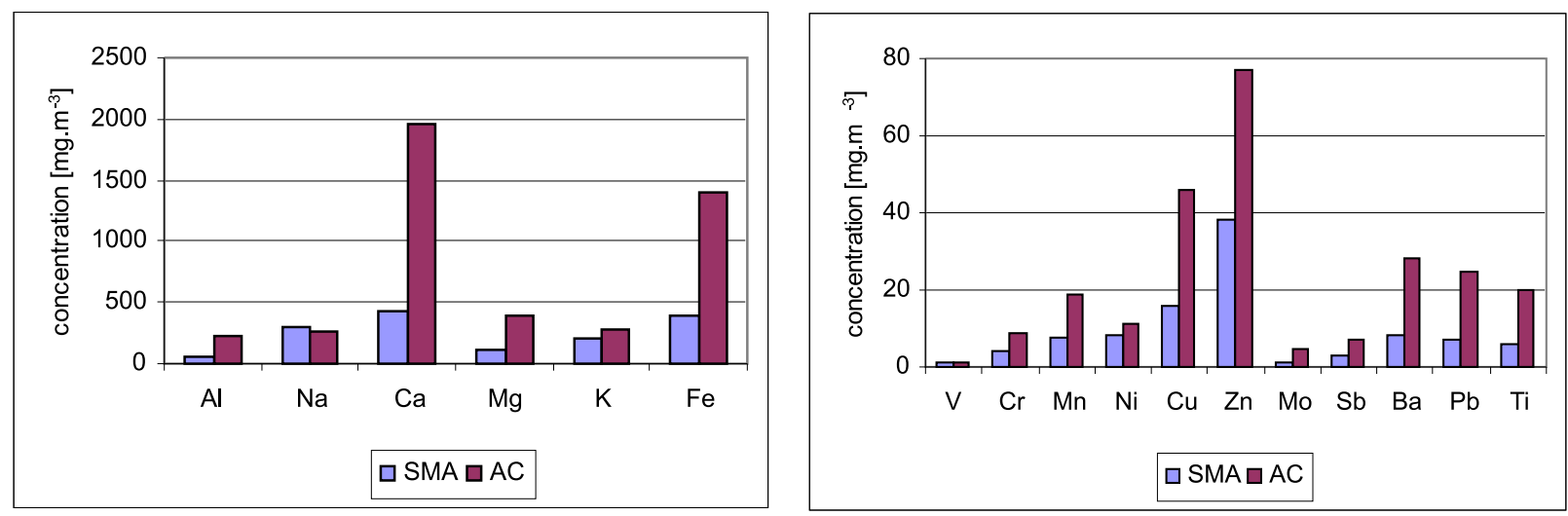

Fig. 12 Content of selected substances in PM10 fraction - position 1 - I/18 Zilina through road [1]

Contents of selected metals, representing sources related to mechanical abrasion of particles, such as $\mathrm{Zn}, \mathrm{Sb}, \mathrm{Cu}, \mathrm{Ba}$ and other, were identified in both fine and coarse PM fractions. Contents of selected metals in both PM fractions were higher at sites with asphalt-concrete pavement at both collection campaigns, except $\mathrm{K}$ and $\mathrm{Pb}$ in the second collection campaign in the autumn (Fig. 12).

\section{Discussion about Results}

According to foreign studies, abrasion of tyres, brake shoe lining and roadway contributes significantly to non-combusted traffic emissions. For example [6] or [7] suggest that the share of noncombusted PM10 emissions in total traffic pollution is $50 \%$ at present and $50 \%$ comes from combustion processes. Considering the renewal of vehicle fleets and use of new fuel types it is likely that the share of non-combustion emissions will become higher.

Analysis of principal components (PCA) for emission source quantification in transport was done by [5]. A component analysis transforms initial variables into orthogonal quantities summarising variances of the initial variables. However, it is up to interpretation whether these new components represent artificial characteristics or whether they reflect real factors.

Thurston [5] specifies the substances that achieve the highest component values. For tyre and brake shoe lining abrasion, these are benzothiazole, zinc $(\mathrm{Zn})$, copper $(\mathrm{Cu})$, antimony $(\mathrm{Sb})$, titanium (Ti), nickel $(\mathrm{Ni})$; for roadway abrasion, these are nickel $(\mathrm{Ni})$ and vanadium $(\mathrm{V})$; and calcium $(\mathrm{Ca})$, aluminium $(\mathrm{Al})$ a barium (Ba) in case of resuspendation.

Based on the chemical analysis done at measuring stations (Fig. 12) it can be assumed that the data obtained on higher $\mathrm{Ca}, \mathrm{Zn}$, and $\mathrm{Cu}$ values among the chemical substances monitored show that the particulates captured in flow pump filters can originate from tyre and brake shoe lining abrasion and resuspendation. The share of road surface abrasion is negligible. Comparison of effects of roadway surface clearly shows that abrasion of components was higher on a roadways made from asphalt concrete than on roadways made with mastic asphalt surface.

These are just partial results of our research work. The monitoring should be complemented by other measurements to have sufficient number of samples for a relevant statistical evaluation. This research work is under way.

\section{Acknowledgement:}

This contribution is the result of the project implementation:

Centre of excellence for systems and services of intelligent transport, ITMS 26220120028 supported by the Research \& Development Operational Programme funded by the ERDF and in terms of the scientific research task VEGA 1/0673/08 Impact of Roadway Serviceability on Road Traffic Immissions.

\begin{tabular}{|c|c|c|c|c|c|c|}
\hline Share & $\begin{array}{c}\text { Unidentified } \\
\text { source }\end{array}$ & $\begin{array}{c}\text { Diesel } \\
\text { combustion }\end{array}$ & $\begin{array}{c}\text { Petrol } \\
\text { combustion }\end{array}$ & Re-suspension & $\begin{array}{c}\text { Abrasion of tyres } \\
\text { and brakes }\end{array}$ & $\begin{array}{c}\text { Abrasion } \\
\text { of roadway }\end{array}$ \\
\hline$\%$ & 7.9 & 25.0 & 21.6 & 10.7 & 22.6 & 12.2 \\
\hline
\end{tabular}



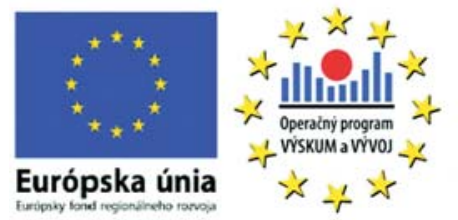

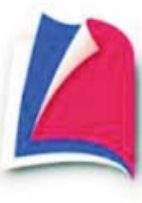

Agentúra

Ministerstva školstva, vedy, výskumu a športu SR pre štrukturálne fondy EÚ

“Podporujeme vyskumne aktivity na Slovensku/Projekt je spolufinancovany zo zdrojov EU.”

\section{References}

[1] DURCANSKA, D., HUZLIK, J., LICBINSKY, R.: Monitoring the Effects of Pavement on Composition of Particulate Matter, Sustainable development and bioclimate. In: Reviewed proc. from the scientific international conference. The High Tatras: Stara Lesna, 2009, Geophysical Institute of the SAS, ISBN 978-80-900450-1-9, pp.193-194.

[2] FULleR, G.W., CARSLAW, D.C., LODGE, H.W.: An Empirical Approach for the Prediction of Daily Mean PM10 concentrations. In: Atmos. Environ., p. 36, 1431-1441, 2002.

[3] HAIDER, M. et al.: Guidelines for the Environmental Assessment of Various Pavement Types Including Recommendations to Roads Authorities in NMS, In: WP5 Environmental Assessment, Sustainable Pavements for [1] European New Member States, Activity report, Vienna, p. 97, 2009.

[4] SNILSBERG, B., MYRAN, T. UTHUS, N., ERICHSEN, E.: Characterization of Road Dust in Trondheim, Norway. In: Proc. of the 8th International Symposium on Cold Region Development, ISCORD. Tampere, Finland, 2007.

[5] THURSTON, G.D.: A Source Apportionment of Particulate Air Pollution in Metropolitan Boston, Doctoral dissertation, Dept. of Environ. Health Sci., School of Public Health: Harvard University: Boston, Massachusetts, 1983.

[6] BOULTER, Paul: Non - exhaust Particle Emissions from Road Vehicles, Paper presented at COST 364 PARTICULATES \& ARTEMIS dissemination event, Antwerp, 2004.

[7] LOHMEYER, A., BACHLIN, W., DURING, I.: Modelling of Vehicle Induced non Exhaust PM10 Emissions. Paper presented at PM Emission Inventories Scientific Workshop, Lago Maggiore, Italy, 2004.

[8] STN EN 12341: Ochrana ovzdusia [Air Protection]. Determination of PM10 Fraction of Suspended Particulate Matter, 2001 (in Slovak).

[9] STN EN14907: Ochrana ovzdusia [Air Protection]. Vonkajsie ovzdusie [Ambient Air]. Standard Gravimetric Measurement Method for the Determination of the PM2.5 Fraction of Suspended Particulate, 2005 (in Slovak).

[10] STN ISO 10473: Ochrana ovzdusia [Air Protection]. Vonkajsie ovzdusie [Ambient Air]. Measurement of the Mass of Particulate Matter on a Filter Medium. Beta-ray absorption method, 2003 (in Slovak). 